\title{
Endocrine regulation of circadian physiology
}

\author{
Anthony H Tsang, Mariana Astiz, Maureen Friedrichs and Henrik Oster \\ Medical Department I, University of Lübeck, Lübeck, Germany
}

Correspondence

should be addressed

to $\mathrm{H}$ Oster

Email

henrik.oster@uksh.de

\begin{abstract}
Endogenous circadian clocks regulate 24-h rhythms of behavior and physiology to align with external time. The endocrine system serves as a major clock output to regulate various biological processes. Recent findings suggest that some of the rhythmic hormones can also provide feedback to the circadian system at various levels, thus contributing to maintaining the robustness of endogenous rhythmicity. This delicate balance of clock-hormone interaction is vulnerable to modern lifestyle factors such as shiftwork or high-calorie diets, altering physiological set points. In this review, we summarize the current knowledge on the communication between the circadian timing and endocrine systems, with a focus on adrenal glucocorticoids and metabolic peptide hormones. We explore the potential role of hormones as systemic feedback signals to adjust clock function and their relevance for the maintenance of physiological and metabolic circadian homeostasis.
\end{abstract}

$\begin{aligned} & \text { Key Words } \\ & \text { - circadian rhythms } \\ & \text { - glucocorticoid } \\ & \text { - HPA axis } \\ & \text { - insulin } \\ & \text { - leptin }\end{aligned}$

Journal of Endocrinology (2016) 230, R1-R11

\section{Introduction}

Endogenous circadian clocks regulate a broad spectrum of biological functions via multiple routes. A major output pathway of the circadian clock is the endocrine system which allows for a systemic coordination of various physiological target systems according to the time of day. It has long been appreciated that many hormones show circadian rhythms in the circulation (Pincus et al. 1954, Moore \& Eichler 1972). Both central and peripheral tissue clocks impinge on such endocrine rhythms. On the other hand, hormonal signals have been shown to feed back on circadian clock regulation. Modern life styles compromise the integrity of this feedback balance, and targeting the interaction between the two systems may provide novel solutions to improve general well-being. Various previous reviews have discussed clock regulation of specific hormonal systems (Haus 2007, Kalsbeek \& Fliers 2013) as well as the impact of circadian misalignment in metabolic disorders (Marcheva et al. 2013). Here, we http://joe.endocrinology-journals.org DOI: $10.1530 / J O E-16-0051$
() 2016 Society for Endocrinology Printed in Great Britain Published by Bioscientifica Ltd. describe the clock-endocrine crosstalk with a focus on the hypothalamic-pituitary-adrenal (HPA) stress axis and peptide hormones involved in energy homeostasis (Fig. 1).

\section{Molecular and anatomical makeup of the mammalian circadian system}

The mammalian cellular clockwork consists of a transcriptional-translational feedback loop (TTL) of a set of core clock genes, with a positive and a negative arm active during subjective night and day time, respectively. The positive arm comprised circadian locomotor output cycles kaput (CLOCK) (in neural and vascular tissues, CLOCK can be functionally replaced by neuronal PAS domain-containing protein 2 (NPAS2)) and brain and muscle aryl hydrocarbon receptor nuclear translocatorlike 1 (BMAL1). These transcription factors form

This article is adapted from work presented at the European Biological Rhythm Society (EBRS)/World Congress of Chronobiology (WCC) meeting, 2-6 August 2015.

The meeting was supported in part by the fournal of Endockinology.04/26/2023 03:49:06 AM 


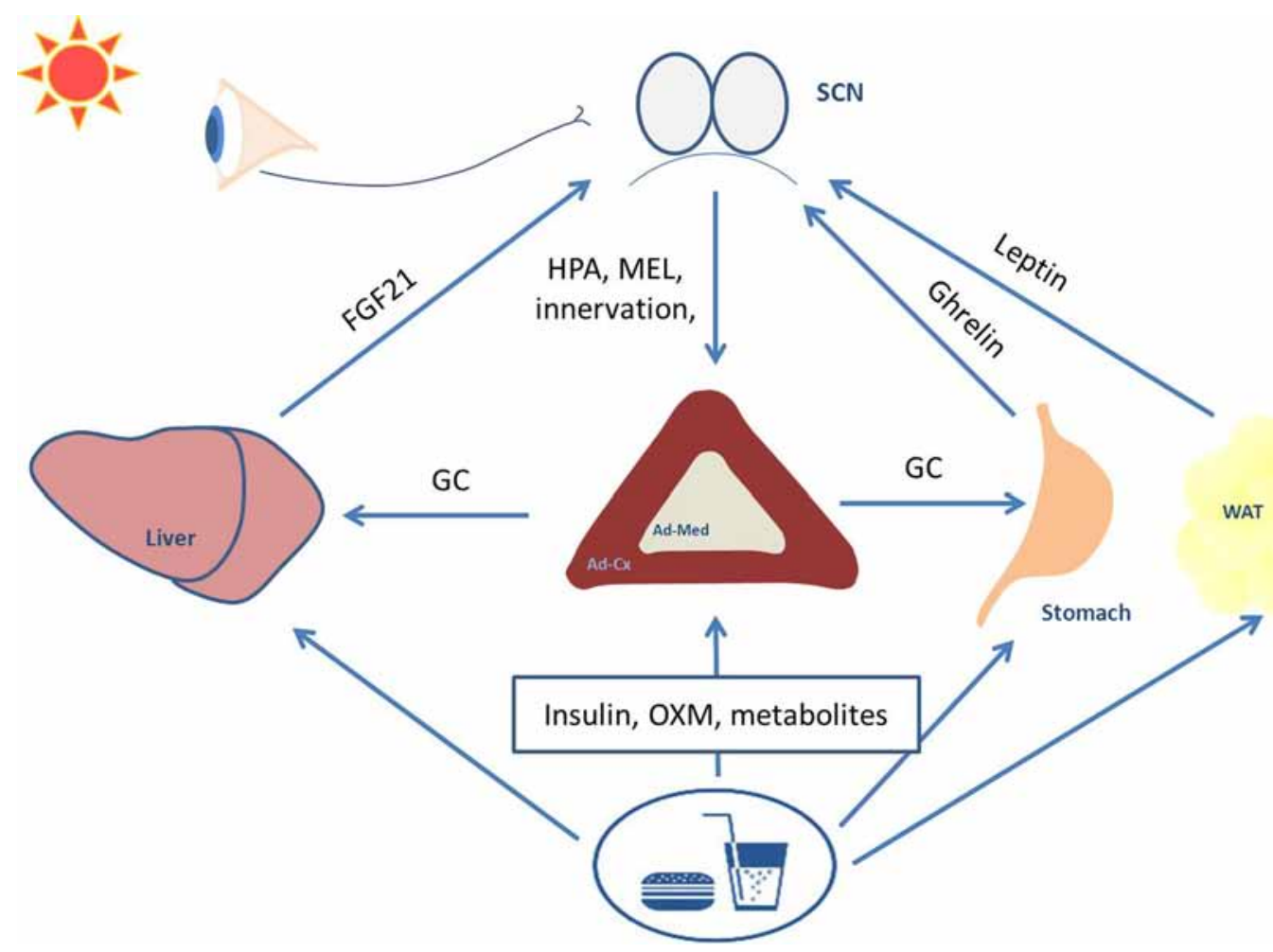

Figure 1

Schematic summary of circadian-endocrine crosstalk. Clocks in the SCN are reset by the external light-darkness cycle. The SCN regulates peripheral physiology via controlling behaviors, hormonal factors, and autonomic innervations. The HPA axis is one major hormonal output of the SCN, which is controlled by direct innervation of the PVN and the subparaventricular zone and further modulated by SCN-controlled melatonin (MEL) secretion. On the other hand, adrenocortical clocks provide a circadian gating mechanism regulating ACTH sensitivity of the adrenal cortex. GC rhythms act as synchronizing signals of peripheral tissues, but not the $\mathrm{SCN}$, by directly resetting clock gene expression in target tissues. Peripheral clocks are also reset by food intake mediated by hormonal factors such as insulin and oxyntomodulin, as well as by various metabolites such as glucose and fatty acids. Some metabolic hormones such as leptin, ghrelin, and FGF21 are regulated by interplay of the clock and food intake, but they also provide metabolic feedback to the SCN to modify circadian behaviors. SCN, suprachiasmatic nucleus; HPA, hypothalamic adrenocortical axis; MEL, melatonin; ACTH, adrenocorticotropic hormone; GC, glucocorticoid, FGF21, fibroblast growth factor.

heterodimers which bind to E-box promoter elements to activate the negative arm genes, period (Per1-3) and cryptochrome (Cry1/2), as well as several other clockcontrolled genes (CCGs). During the night, CRY and PER proteins accumulate in the cytoplasm and translocate into the nucleus where they inhibit CLOCK:BMAL1 activity and, thus, shut down their own transcription. Subsequent degradation of PER and CRY relieves the inhibition on CLOCK:BMAL1 toward the morning, followed by resumed transcription of Per/Cry and other CCGs. The cycle is further stabilized by accessory TTLs such as the one composed of the nuclear receptors $\mathrm{REV}-\mathrm{ERB} \alpha / \beta$ and ROR $\alpha / \beta$, repressing and activating Bmal1 transcription, respectively (Zhang \& Kay 2010).

The mammalian circadian system is organized in a hierarchical manner. The molecular clockwork described above is present in essentially all cells, but the nature of CCGs differs between tissues (Zhang et al. 2014). In order to generate physiologically meaningful rhythms, these tissue clocks have to be properly aligned with each other and external time. In mammals, light is the major Zeitgeber (German for 'time giver'). A master pacemaker located in the hypothalamic suprachiasmatic nucleus (SCN) acts as the major interface between endogenous rhythms and environmental time cues such as the light-darkness cycle (Husse et al. 2015). The SCN receives photic input from intrinsically photoreceptive retinal ganglion cells (ipRGCs) expressing the photopigment melanopsin to entrain SCN clock gene expression and neuronal activity (Hankins et al. 2008). The majority of efferent projections from the SCN target hypothalamic structures such as the subparaventricular zone (sPVZ), the arcuate nucleus (ARC), the paraventricular nucleus (PVN), and the dorsomedial hypothalamic nucleus (DMH). Through these, the SCN regulates a plethora of physiological systems (Saeb-Parsy et al. 2000). Mice with focal SCN lesions lose circadian

Published by Bioscientifica Ltd. 
behavioral and physiological rhythms and no longer entrain to light-darkness cycles (Moore \& Eichler 1972, Stephan \& Zucker 1972). It is still a matter of debate as to which of these functions require rhythmic input from the SCN and which are primarily controlled by clocks in downstream central or peripheral tissues. Environmental factors other than light can serve as Zeitgebers of the circadian system. For example, temporally restricted food availability is a potent synchronizer of peripheral tissue and some central nervous system (CNS) clocks, but has little effect on the SCN itself (Damiola et al. 2000, Stephan 2002).

\section{Circadian regulation of the HPA axis}

Many hormones and most of the major endocrine axes show robust circadian rhythms. Of these, circadian regulation of the HPA axis is particularly well studied, since blood levels of glucocorticoids (GCs) are among the most rhythmic functions observed in the mammalian system and because both GCs and catecholamines have been implicated in the synchronization of circadian clocks and rhythms in other tissues (Balsalobre et al. 2000, Terazono et al. 2003). HPA axis activity coordinates different physiological systems and behavior in response to stress. GCs are the end products of the activation of the HPA axis. Acute stress activates hypothalamic release of corticotropin-releasing hormone (CRH) to the anterior pituitary, where it stimulates the release of adrenocorticotropic hormone (ACTH) into the bloodstream. ACTH activates adrenocortical steroidogenesis through the melanocortin 2 receptor (MC2R), via a cyclic adenosine monophosphate/protein kinase A (cAMP/PKA)-dependent pathway (Miller \& Bose 2011). Under nonstressed conditions, blood GC levels oscillate in both circadian and ultradian manners. Ultradian (aka. pulsatile) GC rhythms are controlled by a negative feedback loop in which GCs suppress ACTH production via the hypothalamus and the pituitary (Spiga et al. 2014). The circadian GC rhythm, in contrast, involves HPA activity, SCN-controlled autonomic innervation, and adrenocortical clocks. The peak of the circadian GC rhythm is phase-locked to the beginning of the active phase in order to organize various biological processes to prepare for the active behavior during the wake time (Moore \& Eichler 1972). Circadian GC rhythms have long been established as a function of endogenous circadian clocks as they persist even under constant conditions. At the same time, surgical ablation of the SCN completely abolishes the circadian release of GCs into the blood (Moore \& Eichler 1972). Retrograde neuronal tracing experiments revealed that the adrenal is connected to the SCN via the intermediolateral (IML) column of the spinal cord and the PVN (Buijs et al. 1999). Sympathetic nerve stimulation potentiates GC responses, suggesting a role of adrenal sympathetic innervation in the regulation of GC rhythms (Edwards \& Jones 1993). The SCN projects inhibitory efferents to pre-autonomic and CRH-producing neurons in the PVN which ultimately lead to a suppression of adrenal GC secretion (Buijs et al. 1997). On the other hand, HPA axis activity upstream of the adrenal is also rhythmic, so circadian GC release may be an indirect response to SCN-controlled CRH expression. The latter view has been challenged by the discovery that the timing of expression of $\mathrm{CRH}$ in the hypothalamus and pro-opiomelanocortin (POMC) in the anterior pituitary and the plasma surge of GC is not organized in the expected sequential manner (Girotti et al. 2009). Moreover, in hypophysectomized rats, the implantation of constant-release ACTH pellets is sufficient to restore GC rhythmicity (Ottenweller \& Meier 1982). Along this line, light signals have been found to be capable of modulating adrenal GC secretion via the SCN directly and independent of ACTH (Buijs et al. 1999, Ishida et al. 2005).

Experiments from the early 1960s suggested that the responsiveness of the adrenal steroidogenic machinery to ACTH stimulation shows circadian variations (Ungar $\&$ Halberg 1962). More than 40 years later, our group described an SCN-independent, adrenal clock-controlled gating mechanism underlying this observation (Oster et al. 2006). As a consequence, surgical or genetic ablation of adrenal clock function in mice results in dampened rhythms of GC secretion compared with sham-treated or wild-type controls (Oster et al. 2006, Son et al. 2008). Son and coworkers further showed that steroidogenic acute regulatory protein (StAR), one of the pacemakers of GC biosynthesis, is a direct target of CLOCK:BMAL1, suggesting a mechanistic function of adrenocortical clocks in the regulation of GC production (Son et al. 2008). The light pulse data discussed above suggest that adrenal clocks are entrained by neuronal mechanisms (Buijs et al. 1999, Ishida et al. 2005). However, Yoder and coworkers recently found that ACTH itself can also shift the phase of the adrenal Per2 rhythm (Yoder et al. 2014). One might speculate that, in this way, stress-induced HPA axis activation can reset adrenal clocks, thus affecting circadian GC release. Also, under acute stress conditions, the circadian clock plays a role in HPA axis regulation. SCN-lesioned animals show

Published by Bioscientifica Ltd. 
exaggerated GC secretion under acute stress, in line with an inhibitory role of the SCN on HPA axis activity (Buijs et al. 1997, 1999). Interestingly, we recently reported that Bmal1-deficient mice show a blunted stress-induced GC release along with reduced behavioral responses (Leliavski et al. 2014). Together, these data suggest that repetitive or chronic stress may alter the timing of GC-regulated metabolic processes. Not only GC production but also GC action has been found to be gated by the molecular clock. GC receptors (GRs) are rhythmically expressed in various tissues and subject to acetylation (and subsequent inactivation) by CLOCK (Charmandari et al. 2011). Recently, CRY1/2 proteins have been shown to directly repress the transactivational function of GR in a ligand-dependent manner (Lamia et al. 2011), providing another layer of complexity to the circadian regulation of GR signaling.

The pineal hormone melatonin may serve as an additional mean for the SCN to further modulate HPA axis activity. Melatonin secretion is controlled via multisynaptic innervation by the SCN pacemaker and plays a role in synchronizing peripheral tissue clocks (Hardeland et al. 2012). Melatonin administration suppresses HPA axis activity (Konakchieva et al. 1997, Torres-Farfan et al. 2003), and timed melatonin administration can entrain adrenal gland rhythms (Torres-Farfan et al. 2011). Together, melatonin and GC rhythms appear to act in concert to stabilize circadian phase and precision of different physiological systems.

\section{Circadian regulation of metabolic hormones}

Recent studies highlight the importance of the circadian clock in metabolic regulation. Behaviorally arrhythmic mice under constant light conditions (LL) or SCNlesioned animals show increased body-weight gain together with impaired glucose tolerance and insulin sensitivity (Fonken et al. 2010, Coomans et al. 2013). Likewise, various metabolic phenotypes have been reported for different clock gene mutations (Bechtold \& Loudon 2013). For instance, Bmal1-knockout (KO) mice display impaired glucose homeostasis with reduced gluconeogenesis and glucose intolerance (Rudic et al. 2004, Lamia et al. 2008, Marcheva et al. 2010, Kennaway et al. 2013), while Clock $\Delta 19$-mutant mice are obese and show hyperglycemia and hyperlipidemia (Turek et al. 2005). These and other metabolic disturbances are accompanied by altered endocrine functions. Both the master SCN clock and local clocks in peripheral tissues are involved in regulating the production and function of several metabolic hormones. Below, we summarize recent findings on the circadian regulation of insulin and its function in glucose homeostasis and on the ghrelinleptin system controlling feeding behavior.

\section{Circadian gating of insulin function in glucose homeostasis}

Circulating plasma glucose levels, insulin concentrations, and whole-body insulin sensitivity display SCNdependent circadian variations (La Fleur et al. 1999, Rudic et al. 2004, Lamia et al. 2008, Shi et al. 2013). Local clocks in pancreatic beta cells provide a gating mechanism for insulin secretion. Disruption of the positive arm of this clock (i.e. tissue-specifically deleting Clock or Bmal1) results in hypoinsulinemia (Marcheva et al. 2010, Sadacca et al. 2011), whereas deletion of the clock's negative regulators (i.e. the Pers or Crys) is associated with hyperinsulinemia (Barclay et al. 2012, Zhao et al. 2012). In rodent and human pancreatic beta cells, the main functional targets of the clock machinery are a number of CCGs involved in peptide secretory pathways (Perelis et al. 2015, Saini et al. 2016). This mechanism further appears to be sensitive to the cellular redox status. Normalizing reactive oxygen species (ROS) levels can partially rescue the impairment of insulin secretion in Bmal1-deficient pancreatic beta cells (Sadacca et al. 2011). In line with these observations, mice with behaviorally disrupted circadian rhythms also exhibit hypoinsulinemia (Sadacca et al. 2011). Intriguingly, SCNlesioned mice show hyperinsulinemia, but this may rather be an effect of elevated body weight and systemic insulin resistance (Coomans et al. 2013). Further studies will be needed to elucidate how SCN and local pancreatic clocks interact in regulating insulin secretion.

Circadian clocks play a further role in regulating insulin sensitivity at target tissues. Insulin resistance, a hallmark of the prediabetic state, has been associated with extended shift work in humans (Esquirol et al. 2012). Liver, skeletal muscle, and adipose tissues are the major effector organs of insulin's hypoglycemic effects. Cell-type-specific Bmal1-mutant mice have been used to assess the role of the molecular clock in regulating insulin sensitivity in these tissues. Bmal1-knockout mice show impaired systemic insulin sensitivity accompanied by hyperglycemia over the course of a day (Rudic et al. 2004, Lamia et al. 2008, Shi et al. 2013). In contrast, mice with liver-specific deletion of Bmal1 show improved glucose tolerance, lowered blood glucose, but normal systemic 
insulin sensitivity (Lamia et al. 2008). Hypoglycemia in these mice may be explained by blunted expression of GLUT2, which mediates the export of glucose from liver to the blood stream (Lamia et al. 2008). Alternatively, CRY1 has been shown to modulate gluconeogenesis by its interaction with the G-protein involved in glucagon signaling pathway (Sun et al. 2015) and PER2 binds to regulatory regions of the glucose-6-phosphatase gene, a key player in maintaining glucose levels during fasting periods (Schmutz et al. 2010). Skeletal muscle clocks have been suggested to play a role in preparing the transition from the rest/fasting to the active/feeding phase of the day when glucose becomes the predominant fuel. Skeletal muscle-specific Bmal1-knockout mice show impaired insulin-stimulated glucose uptake due to downregulated GLUT4 expression. However, the canonical insulin signaling pathway appears unaltered in these animals, as do systemic insulin sensitivity and blood glucose concentrations (Dyar et al. 2014). Skeletal muscle itself is an endocrine organ which secretes a number of peptide hormones known as myokines. Using human primary skeletal myotubes as a model, a recent study has unveiled that the clock machinery plays a pivotal role in regulating basal and circadian secretion of several myokines (Perrin et al. 2015). Given that many myokines are established regulators of energy metabolism, disruption of muscle clocks may link circadian misalignment to metabolic diseases. Adipose physiology shows strong variations over the course of the day. Adipocyte-specific Bmal1-knockout mice develop obesity. Surprisingly, though, these mice display normal systemic insulin sensitivity and glucose homeostasis (Paschos et al. 2012). Instead, the obesity phenotype appears to stem from mistimed feeding induced by altered adipose production of polyunsaturated fatty acids (Paschos et al. 2012).

\section{Circadian regulation of leptin and ghrelin}

The timing of food intake has recently been found to play an unexpected key role in body energy homeostasis (Zarrinpar et al. 2016). For example, scheduled feeding of a high-fat diet (HFD) during the inactive phase in mice leads to significant increase in body weight compared with feeding during the normal active phase, despite comparable caloric intake (Kohsaka et al. 2007). In line with that, scheduled feeding during the active phase (i.e. the night in nocturnal rodents) is protective against the metabolic dysregulation induced by HFD compared with chow fed controls ad libitum (Chaix et al. 2014).
In a recent study in humans, restricting food intake to $12 \mathrm{~h}$ during the day had beneficial effects on body-weight control (Gill \& Panda 2015). The relative abundance of the antagonistic hormone duo, ghrelin and leptin, plays a major role in determining appetite regulation via signaling to the mediobasal hypothalamus (MBH) (Begg \& Woods 2013). Blood levels of both hormones display circadian rhythms and are subject to acute regulation by food intake (see below).

Leptin is a cytokine-like peptide secreted from adipocytes to suppress food intake. In most obese individuals, leptin fails to suppress appetite despite increased blood leptin concentrations; a condition that has, in reference to insulin resistance in type 2 diabetes, been termed leptin resistance, though the mechanism of this lack of leptin action has still to be determined (Begg \& Woods 2013). Baseline plasma leptin levels show SCN-dependent circadian variations (Kalsbeek et al. 2001) which are blunted and elevated in Clocks19, Bmal1-knockout, as well as adipose-specific Bmal1-deficient mice (Turek et al. 2005, Paschos et al. 2012, Kennaway et al. 2013). Owing to increased fat mass in these genetic models, it has not yet been conclusively shown to which extent in vivo leptin secretion rhythms are directly regulated by adipocyte clocks or rather follow systemic cues such as food intake. Nevertheless, in vitro leptin secretion rhythms persist in cultured adipocytes (Otway et al. 2009). A recent study has identified an unexpected dual role of BMAL1:CLOCK in Leptin (Lep) transcription via an interaction with CCAAT/enhancer-binding protein $(\mathrm{C} / \mathrm{EBP} \alpha)$ at the proximal Lep promoter. When blood leptin levels are at their trough (corresponding to the early inactive phase in mice), CLOCK:BMAL1 modestly enhances the C/EBP $\alpha-$ mediated upregulation of Lep transcription, while acting in a suppressive way at high leptin blood levels (i.e. during the late inactive phase) due to direct competition with $\mathrm{C} / \mathrm{EBP} \alpha$ for Lep promoter binding (Kettner et al. 2015). In the same study, the authors also demonstrated that central leptin sensitivity is impaired in mice with genetically or behaviorally disrupted circadian rhythms (Kettner et al. 2015). How the molecular clock influences hypothalamic leptin signaling, however, remains unclear.

Ghrelin, on the other hand, is an orexinergic hormone secreted from the gastrointestinal (GI) tract in response to fasting. Both circulating ghrelin and gastric preproGhrelin (Ghrl) mRNA levels display circadian rhythms which are lost in Bmal1-mutant mice (LeSauter et al. 2009, Laermans et al. 2015). Intriguingly, local GI clocks appear to be dispensable for regulating ghrelin secretion, as
Published by Bioscientifica Ltd. 
siRNA-mediated downregulation of Bmal1 failed to affect ghrelin secretion from ghrelinoma cells (Laermans et al. 2015). Despite its role as a peripheral feedback signal to the central circadian system (see below), very little is still known about how the circadian system affects ghrelin secretion and sensitivity.

\section{Endocrine feedback on the circadian system}

Recent data suggest that endocrine functions are not merely an output of the circadian clock system, but also serve as feedback signals to regulate the circadian system at various levels. Alterations of such endocrine feedback have been implicated in the circadian disruption associated with conditions such as sleep disorders or shift work. In the following paragraphs, we will discuss the physiological relevance of hormones on the regulation of circadian rhythms with a focus on GCs and metabolic peptide hormones.

\section{GC circadian clock feedback}

As outlined above, the rhythmic secretion of GCs is involved in entraining clocks of peripheral and CNS tissues. GR is ubiquitously expressed throughout the body, with the notable exception of the SCN (Okamura 2007). It exerts a plethora of physiological effects by binding to GC-responsive elements (GREs) in the promotor of target genes and upregulating their expression (Yamazaki et al. 2009). The mechanism of GC-induced resetting of local clocks has been described. The proximal promotors of Per genes contain GREs and, thus, are activated by GCs to reset the phase of the TTL, very comparable to lightinduced resetting of SCN clocks (Balsalobre et al. 2000). Very recently, a novel consensus promoter GR regulatory sequence ( $n G R E$ ) has been discovered, binding of which results in repression of target gene transcription (Surjit et al. 2011). An auxiliary clock gene (Dec1) contains an $n G R E$ in its promoter (Surjit et al. 2011). The two DEC proteins (DEC1/2; aka. BHLHE40/1) have been shown to modify the molecular clock in a tissue-specific manner (Rossner et al. 2008, Tsang et al. 2012). How GC-induced Dec suppression may affect tissue clock function, however, has not yet been studied.

Given the stimulatory role of GCs in arousal and alertness, it is not surprising that due to disruption of GC rhythms (such as in Cushing's (hypercortisolemia), Addison's (hypocortisolemia), and chronic stress dieseases) patients often suffer from sleep and circadian rhythm disorders (Leliavski et al. 2015). For Addison's patients, the standard therapeutic approach involves lifelong supplementation of GCs which often fails to replicate the normal circadian GC rhythm, thus compromising the patients' quality of life (Arlt \& Allolio 2003). Attempts to modify the release profiles of GC replacement medications aimed to mimic the natural GC circadian rhythm have shown promising improvements in clinical studies (Chan \& Debono 2010), highlighting the physiological importance of the circadian GC rhythm.

Transcontinental flight travel across multiple time zones results in jetlag which manifests in transient physiological and behavioral disturbances such as decreased alertness during the day and sleep problems during the night. It has been shown that GC rhythms are involved in mediating the adaptation of internal rhythms under jetlag conditions. In mice, by manipulating GC secretion phase during jetlag, behavioral adaptation after a shift of the light-darkness cycle can be accelerated (Kiessling et al. 2010). The potential clinical use of this treatment in humans warrants further pursuit.

\section{Metabolic hormone circadian clock feedback}

As outlined above, the timing of food intake is a major Zeitgeber to clocks residing in, both, the periphery and the CNS. When food access is restricted to the inactive phase of mice, it uncouples peripheral clocks from the SCN pacemaker (Damiola et al. 2000). In consequence, mistimed feeding alters circadian rhythms of locomotor activity and of various endocrine functions (Zarrinpar et al. 2016). Interestingly, already a mere change in nutrient composition can affect circadian rhythm regulation. Mice fed a high-fat diet ad libitum show blunted behavioral and molecular circadian rhythms (Kohsaka et al. 2007). These effects are correlated with altered regulation of metabolic hormone secretion.

All three metabolic hormones discussed above can provide feedback to the circadian clock system. Insulin has been shown to regulate food-induced resetting of liver clocks in vitro and in vivo, though the underlying mechanism has not yet been described (Tahara et al. 2011, Yamajuku et al. 2012). Our group has recently identified the incretin hormone oxyntomodulin (OXM) as an additional effector of food entrainment of peripheral tissues clocks (Landgraf et al. 2015). OXM is a 37-amino acid peptide of the glucagon family secreted from GI cells after meal intake. It promotes gastric acid secretion 
and gut motility, but suppresses appetite. Both glucagon (GCGR) and glucagon-like peptide 1 receptors (GLP-1R) have been shown to mediate a part of OXM signaling, but an, as yet uncharacterized, additional pathway has been suggested (Pocai 2014). In our study, we found that, in the inactive phase, postprandial increases of blood OXM levels are sufficient to reset the molecular clock and clock output gene rhythms in liver via a glucagon receptordependent signaling mechanism and induction of hepatic Per expression (Landgraf et al. 2015). Paradoxically, at a different time of day, glucagon itself can enhance fasting-induced liver Bmal1 expression (Sun et al. 2015). Further studies are needed to evaluate the temporal order and relative contributions of these and other metabolic hormones in mediating feeding-associated resetting of circadian transcriptional programs in peripheral tissues. Along this line, using a novel screening approach, Gerber and coworkers identified serum response factor (SRF) as an immediate early response transcription factor in the liver relaying signals from as yet unidentified oscillating blood-borne factors to control liver clock gene expression (Gerber et al. 2013).

Fibroblast growth factor 21 (FGF21) is a metabolic hormone that has recently been found to directly regulate circadian behavior and energy homeostasis via the SCN (Bookout et al. 2013). FGF21 is mainly produced by the liver, but is also secreted from muscle and white adipose tissues. Its signals are mediated via its cognate receptors (FGF receptors FGFR1c, FGFR2c, or FGFR3c) in complex with $\beta$-Klotho abundantly expressed in metabolic tissues (Degirolamo et al. 2016). FGF21 plays a major role in adaptive responses under starvation. The secretion of FGF21 is stimulated by fasting to enhance energy mobilization through gluconeogenesis, fatty acid oxidation, and ketogenesis (Degirolamo et al. 2016). FGF21 was also found to enhance insulin sensitivity after overfeeding ( $\mathrm{Xu}$ et al. 2009). Together, much attention has been drawn to the therapeutic potential of FGF21 in treating metabolic syndromes. A recent study showed that the expression of the $\beta$-Klotho-encoding Klb gene is highly enriched in the SCN. Overexpression of FGF21 in mice was found to blunt circadian locomotor activity rhythms and suppress insulin, but to enhance GCs secretion and reduce body weight. However, mice with conditional genetic ablation of $K l b$ in the SCN lack these phenotypes, suggesting that the metabolic FGF21 effects are dependent of SCN clock function (Stephan 2002). Additionally, the FGF21-SCN axis has been found to play a key role in regulating female fertility via vasopressin-kisspeptin signaling controlling the proestrus surge of luteinizing hormone (Owen et al. 2013).

Both leptin and ghrelin can also directly regulate SCN function. In explant slices, leptin stimulation can reset the phase of SCN neuron firing rhythms (Prosser \& Bergeron 2003). In vivo, systemic leptin injections result in modest induction of Per expression in the SCN and potentiate the phase-shifting effects of light in female, but not in male mice (Mendoza et al. 2011). Ob/ob mice (carrying a lossof-function mutation of the Lep gene) show altered photic responses of the circadian clock at both behavioral and molecular levels, which can be normalized by timed injections of leptin. In the same study, however, the authors found that systemic leptin injections failed to stimulate canonical leptin signaling cascades in the SCN, suggesting an indirect mechanism for leptin's circadian resetting effects (Grosbellet et al. 2015b). Db/db mice (expressing a nonfunctional version of the long isoform of leptin receptor gene, $\mathrm{Obrb}$ ) show severely disrupted locomotor activity and feeding rhythms together with exaggerated molecular photic responses in the SCN (Grosbellet et al. 2015a). Similar to leptin, ghrelin has been shown to directly impact on the SCN. In vitro, treatment of ghrelin phase resets the circadian neuronal firing and Per expression rhythms in organotypic cultured SCN-containing slices (Yannielli et al. 2007). Likewise, application of a synthetic ghrelin analog in in vivo phase resets circadian locomotor activity rhythms (Yannielli et al. 2007), but attenuates light-induced phase-shifts, which may involve inhibitory innervations from ghrelin-sensitive neurons in the ARC to the SCN (Yi et al. 2008). A recent study has discovered an unexpected role of ghrelin as a circadian regulator of the sleep/wake cycle. Ghrelin-positive neurons, receiving projections from the SCN and the visual system via the intergeniculate leaflet (IGL), suppress the activity of arousal-promoting orexinergic neurons in the lateral hypothalamus (LH) (Horvath et al. 2012).

Anticipatory behavioral activity before scheduled feeding (food anticipatory activity, FAA) is seen in animals with time-restricted access to food (RF) and is characterized by increases in locomotor activity, body temperature, and GC secretion just before feeding time (Krieger et al. 1977). It is believed to reflect foraging in anticipation of food intake. FAA rhythms represent a form of food entrainment of the circadian system as they develop in the absence of other time cues (such as the light-darkness cycle) and persist even when the scheduled feeding condition is lifted (i.e. they free-run) (Mistlberger 2009). Although the anatomical and molecular makeup of this food-entrainable 
oscillator (FEO) underlying FAA rhythms is still largely unknown, both leptin and ghrelin have been shown to play a role in regulating FAA rhythms. $o b / o b$ mice and Obrbmutant Zucker rats show increased FAA under RF, which can be suppressed by the administration of recombinant leptin (Mistlberger \& Marchant 1999, Ribeiro et al. 2011). In contrast, ghrelin receptor (Ghsr)-deficient mice show impaired FAA (Blum et al. 2009, LeSauter et al. 2009, Lamont et al. 2014); though intriguingly, ghrelin-deficient mice are normal under these conditions (Szentirmai et al. 2010). The mechanisms that mediate leptin and ghrelin effects on FAA remain unknown. Two neural substrates have been identified to modify FAA rhythms, which are also established targets of leptin and ghrelin: the dopaminergic reward circuitry Gallardo et al. 2014 and the mediobasal hypothalamic appetite-regulating circuitries centers (Bechtold \& Loudon 2013). The SCN itself has been recognized as a negative regulator of FAA rhythms (Storch \& Weitz 2009, Acosta-Galvan et al. 2011). Given that both of these two hormones can directly act on the SCN clock, it is plausible that the circadian pacemaker may mediate part of their FAA-regulating effects. Alternatively, it has been shown that the DMH is a positive regulator of FAA through suppression of SCN neuronal activity (Acosta-Galvan et al. 2011). The DMH receives input from several metabolic state-sensing brain nuclei such as the ARC (Bouret et al. 2004), thus acting as a relay mediating the FAA effects of metabolic hormones.

\section{Concluding remarks}

The endocrine system serves as a major output of the circadian clock. Circadian disruption is a frequent consequence of modern urban lifestyles. Occupations requiring shift work or irregular working hours, chronic stress, mistimed light exposure, e.g. through artificial lighting or the use of light-emitting electronic devices (Chang et al. 2015), and the frequent intake of arousal stimulating beverages such as coffee at night (Burke et al. 2015) are all established disruptors of the circadian system. Altered circadian hormonal regulation compromises one's health such as by promoting the development of metabolic disorders. At the same time, many hormones have been shown to feed back on the circadian clock system at various levels, thus supporting the maintenance of robust physiological and behavioral rhythms. This central role of endocrine signals within the circadian system makes them attractive targets to manipulate physiological functions via the circadian clock, e.g. to affect circadian stabilization during jetlag (Kiessling et al. 2010) or shift work. The recent discovery of drugs directly impinging on molecular clock function (Hirota et al. 2010, Solt et al. 2012), on the other hand, offers the possibility to ameliorate disrupted endocrine regulation under desynchrony conditions through the circadian clock. Finally, reinstating behavioral and physiological rhythms, e.g. by restricting food intake to the active phase, may protect against metabolic dysregulation (Chaix et al. 2014, Gill \& Panda 2015), providing a highly accessible mean for improving the general well-being.

\section{Declaration of interest}

The authors declare that there is no conflict of interest that could be perceived as prejudicing the impartiality of this review.

\section{Funding}

This work was funded by research grants of the German Research Foundation (DFG; GRK-1957; TR-SFB-134 \& -654), a fellowship of the International Brain Research Organization (IBRO; to $\mathrm{M} \mathrm{A}$ ), and a Lichtenberg Fellowship of the Volkswagen Foundation (to $\mathrm{H} \mathrm{O}$ ).

\section{References}

Acosta-Galvan G, Yi CX, van der Vliet J, Jhamandas JH, Panula P, AngelesCastellanos M, Del Carmen Basualdo M, Escobar C \& Buijs RM 2011 Interaction between hypothalamic dorsomedial nucleus and the suprachiasmatic nucleus determines intensity of food anticipatory behavior. PNAS 108 5813-5818. (doi:10.1073/pnas.1015551108)

Arlt W \& Allolio B 2003 Adrenal insufficiency. Lancet 361 1881-1893. (doi:10.1016/S0140-6736(03)13492-7)

Balsalobre A, Brown SA, Marcacci L, Tronche F, Kellendonk C, Reichardt HM, Schutz G \& Schibler U 2000 Resetting of circadian time in peripheral tissues by glucocorticoid signaling. Science $\mathbf{2 8 9}$ 2344-2347. (doi:10.1126/science.289.5488.2344)

Barclay JL, Husse J, Bode B, Naujokat N, Meyer-Kovac J, Schmid SM, Lehnert H \& Oster H 2012 Circadian desynchrony promotes metabolic disruption in a mouse model of shiftwork. PLOS ONE 7 e37150. (doi:10.1371/journal.pone.0037150)

Bechtold DA \& Loudon AS 2013 Hypothalamic clocks and rhythms in feeding behaviour. Trends in Neurosciences 36 74-82. (doi:10.1016/j. tins.2012.12.007)

Begg DP \& Woods SC 2013 The endocrinology of food intake. Nature Reviews Endocrinology 9 584-597. (doi:10.1038/nrendo.2013.136)

Blum ID, Patterson Z, Khazall R, Lamont EW, Sleeman MW, Horvath TL \& Abizaid A 2009 Reduced anticipatory locomotor responses to scheduled meals in ghrelin receptor deficient mice. Neuroscience 164 351-359. (doi:10.1016/j.neuroscience.2009.08.009)

Bookout AL, de Groot MH, Owen BM, Lee S, Gautron L, Lawrence HL, Ding X, Elmquist JK, Takahashi JS, Mangelsdorf DJ, et al. 2013 FGF21 regulates metabolism and circadian behavior by acting on the nervous system. Nature Medicine 19 1147-1152. (doi:10.1038/ nm.3249)
(C) 2016 Society for Endocrinology Printed in Great Britain
Published by Bioscientifica Ltd. 
Bouret SG, Draper SJ \& Simerly RB 2004 Formation of projection pathways from the arcuate nucleus of the hypothalamus to hypothalamic regions implicated in the neural control of feeding behavior in mice. Journal of Neuroscience 24 2797-2805. (doi:10.1523/ JNEUROSCI.5369-03.2004)

Buijs RM, Wortel J, Van Heerikhuize JJ \& Kalsbeek A 1997 Novel environment induced inhibition of corticosterone physiological evidence for a suprachiasmatic nucleus mediated neuronal hypothalamo-adrenal cortex pathway. Brain Research 758 229-236. (doi:10.1016/S0006-8993(97)00234-5)

Buijs RM, Wortel J, Van Heerikhuize JJ, Feenstra MG, Ter Horst GJ, Romijn HJ \& Kalsbeek A 1999 Anatomical and functional demonstration of a multisynaptic suprachiasmatic nucleus adrenal (cortex) pathway. European Journal of Neuroscience 11 1535-1544. (doi:10.1046/j.1460-9568.1999.00575.x)

Burke TM, Markwald RR, McHill AW, Chinoy ED, Snider JA, Bessman SC, Jung CM, O’Neill JS \& Wright KP Jr 2015 Effects of caffeine on the human circadian clock in vivo and in vitro. Science Translational Medicine 7 305ra146. (doi:10.1126/scitranslmed.aac5125)

Chaix A, Zarrinpar A, Miu P \& Panda S 2014 Time-restricted feeding is a preventative and therapeutic intervention against diverse nutritional challenges. Cell Metabolism 20 991-1005. (doi:10.1016/j. cmet.2014.11.001)

Chan S \& Debono M 2010 Replication of cortisol circadian new advances in hydrocortisone replacement therapy. Therapeutic Advances in Endocrinology and Metabolism 1 129-138. (doi:10.1177/2042018810380214)

Chang AM, Aeschbach D, Duffy JF \& Czeisler CA 2015 Evening use of light-emitting eReaders negatively affects sleep, circadian timing, and next-morning alertness. PNAS 112 1232-1237. (doi:10.1073/ pnas.1418490112)

Charmandari E, Chrousos GP, Lambrou GI, Pavlaki A, Koide H, Ng SS \& Kino T 2011 Peripheral CLOCK regulates target-tissue glucocorticoid receptor transcriptional activity in a circadian fashion in man. PLOS ONE 6 e25612. (doi:10.1371/journal.pone.0025612)

Coomans CP, van den Berg SA, Lucassen EA, Houben T, Pronk AC, van der Spek RD, Kalsbeek A, Biermasz NR, Willems van Dijk K, Romijn JA, et al. 2013 The suprachiasmatic nucleus controls circadian energy metabolism and hepatic insulin sensitivity. Diabetes 62 1102-1108. (doi:10.2337/db12-0507)

Damiola F, Le Minh N, Preitner N, Kornmann B, Fleury-Olela F \& Schibler U 2000 Restricted feeding uncouples circadian oscillators in peripheral tissues from the central pacemaker in the suprachiasmatic nucleus. Genes and Development 14 2950-2961. (doi:10.1101/ gad.183500)

Degirolamo C, Sabba C \& Moschetta A 2016 Therapeutic potential of the endocrine fibroblast growth factors FGF19, FGF21 and FGF23. Nature Reviews Drug Discovery 15 51-69. (doi:10.1038/nrd.2015.9)

Dyar KA, Ciciliot S, Wright LE, Bienso RS, Tagliazucchi GM, Patel VR, Forcato M, Paz MI, Gudiksen A, Solagna F, et al. 2014 Muscle insulin sensitivity and glucose metabolism are controlled by the intrinsic muscle clock. Molecular Metabolism 3 29-41. (doi:10.1016/j. molmet.2013.10.005)

Edwards AV \& Jones CT 1993 Autonomic control of adrenal function. Journal of Anatomy 183 291-307.

Esquirol Y, Bongard V, Ferrieres J, Verdier H \& Perret B 2012 Shiftwork and higher pancreatic early detection of an intermediate state of insulin resistance? Chronobiology International 29 1258-1266. (doi:10.3109/07420528.2012.719959)

Fonken LK, Workman JL, Walton JC, Weil ZM, Morris JS, Haim A \& Nelson RJ 2010 Light at night increases body mass by shifting the time of food intake. PNAS 107 18664-18669. (doi:10.1073/ pnas.1008734107)

Gallardo CM, Darvas M, Oviatt M, Chang CH, Michalik M, Huddy TF, Meyer EE, Shuster SA, Aguayo A, Hill EM, et al. 2014 Dopamine receptor 1 neurons in the dorsal striatum regulate food anticipatory

http://joe.endocrinology-journals.org

DOI: 10.1530/JOE-16-0051
(C) 2016 Society for Endocrinology Printed in Great Britain circadian activity rhythms in mice. Elife 3 e03781. (doi:10.7554/ eLife.03781)

Gerber A, Esnault C, Aubert G, Treisman R, Pralong F \& Schibler U 2013 Blood-borne circadian signal stimulates daily oscillations in actin dynamics and SRF activity. Cell 152 492-503. (doi:10.1016/j. cell.2012.12.027)

Gill S \& Panda S 2015 A smartphone app reveals erratic diurnal eating patterns in humans that can be modulated for health benefits. Cell Metabolism 22 789-798. (doi:10.1016/j.cmet.2015.09.005)

Girotti M, Weinberg MS \& Spencer RL 2009 Diurnal expression of functional and clock-related genes throughout the rat HPA systemwide shifts in response to a restricted feeding schedule. American Journal of Physiology: Endocrinology \& Metabolism 296 E888-E897. (doi:10.1152/ajpendo.90946.2008)

Grosbellet E, Dumont S, Schuster-Klein C, Guardiola-Lemaitre B, Pevet P, Criscuolo F \& Challet E $2015 a$ Circadian phenotyping of obese and diabetic db/db mice. Biochimie 124 198-206. (doi:10.1016/j. biochi.2015.06.029)

Grosbellet E, Gourmelen S, Pevet P, Criscuolo F \& Challet E $2015 b$ Leptin normalizes photic synchronization in male ob/ob mice, via indirect effects on the suprachiasmatic nucleus. Endocrinology 156 1080-1090.

Hankins MW, Peirson SN \& Foster RG 2008 Melanopsin: an exciting photopigment. Trends in Neurosciences 31 27-36. (doi:10.1016/j. tins.2007.11.002)

Hardeland R, Madrid JA, Tan DX \& Reiter RJ 2012 Melatonin, the circadian multioscillator system and the need for detailed analyses of peripheral melatonin signaling. Journal of Pineal Research 52 139-166. (doi:10.1111/j.1600-079x.2011.00934.x)

Haus E 2007 Chronobiology in the endocrine system. Advanced Drug Delivery Reviews 59 985-1014. (doi:10.1016/j.addr.2007.01.001)

Hirota T, Lee JW, Lewis WG, Zhang EE, Breton G, Liu X, Garcia M, Peters EC, Etchegaray JP, Traver D, et al. 2010 High-throughput chemical screen identifies a novel potent modulator of cellular circadian rhythms and reveals CKIalpha as a clock regulatory kinase. PLoS Biology 8 e1000559. (doi:10.1371/journal.pbio.1000559)

Horvath TL, Abizaid A, Dietrich MO, Li Y, Takahashi JS \& Bass J 2012 Ghrelin-immunopositive hypothalamic neurons tie the circadian clock and visual system to the lateral hypothalamic arousal center. Molecular Metabolism 1 79-85. (doi:10.1016/j.molmet.2012.08.003)

Husse J, Eichele G \& Oster H 2015 Synchronization of the mammalian circadian timing Light can control peripheral clocks independently of the SCN alternate routes of entrainment optimize the alignment of the body's circadian clock network with external time. Bioessays $\mathbf{3 7}$ 1119-1128. (doi:10.1002/bies.201500026)

Ishida A, Mutoh T, Ueyama T, Bando H, Masubuchi S, Nakahara D, Tsujimoto G \& Okamura H 2005 Light activates the adrenal timing of gene expression and glucocorticoid release. Cell Metabolism 2 297-307. (doi:10.1016/j.cmet.2005.09.009)

Kalsbeek A \& Fliers E 2013 Daily regulation of hormone profiles. Handbook of Experimental Pharmacology 217 185-226. (doi:10.1007/978-3-642-25950-0)

Kalsbeek A, Fliers E, Romijn JA, La Fleur SE, Wortel J, Bakker O, Endert E \& Buijs RM 2001 The suprachiasmatic nucleus generates the diurnal changes in plasma leptin levels. Endocrinology 142 2677-2685. (doi:10.1210/endo.142.6.8197)

Kennaway DJ, Varcoe TJ, Voultsios A \& Boden MJ 2013 Global loss of bmal1 expression alters adipose tissue hormones, gene expression and glucose metabolism. PLOS ONE 8 e65255. (doi:10.1371/journal. pone.0065255)

Kettner NM, Mayo SA, Hua J, Lee C, Moore DD \& Fu L 2015 Circadian dysfunction induces leptin resistance in mice. Cell Metabolism 22 448-459. (doi:10.1016/j.cmet.2015.06.005)

Kiessling S, Eichele G \& Oster H 2010 Adrenal glucocorticoids have a key role in circadian resynchronization in a mouse model of jet lag. Journal of Clinical Investigation 120 2600-2609. (doi:10.1172/ JCI41192) 
Kohsaka A, Laposky AD, Ramsey KM, Estrada C, Joshu C, Kobayashi Y, Turek FW \& Bass J 2007 High-fat diet disrupts behavioral and molecular circadian rhythms in mice. Cell Metabolism 6 414-421. (doi:10.1016/j.cmet.2007.09.006)

Konakchieva R, Mitev Y, Almeida OF \& Patchev VK 1997 Chronic melatonin treatment and the hypothalamo-pituitary-adrenal axis in the attenuation of the secretory response to stress and effects on hypothalamic neuropeptide content and release. Biology of the Cell $\mathbf{8 9}$ 587-596. (doi:10.1111/j.1768-322x.1997.tb01036.x)

Krieger DT, Hauser H \& Krey LC 1977 Suprachiasmatic nuclear lesions do not abolish food-shifted circadian adrenal and temperature rhythmicity. Science 197 398-399. (doi:10.1126/science.877566)

La Fleur SE, Kalsbeek A, Wortel J \& Buijs RM 1999 A suprachiasmatic nucleus generated rhythm in basal glucose concentrations. Journal of Neuroendocrinology 11 643-652.

Laermans J, Vancleef L, Tack J \& Depoortere I 2015 Role of the clock gene Bmal1 and the gastric ghrelin-secreting cell in the circadian regulation of the ghrelin-GOAT system. Science Reports 516748. (doi:10.1038/srep16748)

Lamia KA, Papp SJ, Yu RT, Barish GD, Uhlenhaut NH, Jonker JW, Downes M \& Evans RM 2011 Cryptochromes mediate rhythmic repression of the glucocorticoid receptor. Nature $\mathbf{4 8 0} 552-556$.

Lamia KA, Storch KF \& Weitz CJ 2008 Physiological significance of a peripheral tissue circadian clock. PNAS 105 15172-15177. (doi:10.1073/pnas.0806717105)

Lamont EW, Bruton J, Blum ID \& Abizaid A 2014 Ghrelin receptorknockout mice display alterations in circadian rhythms of activity and feeding under constant lighting conditions. European Journal of Neuroscience 39 207-217. (doi:10.1111/ejn.12390)

Landgraf D, Tsang AH, Leliavski A, Koch CE, Barclay JL, Drucker DJ \& Oster H 2015 Oxyntomodulin regulates resetting of the liver circadian clock by food. Elife 4 e06253. (doi:10.7554/eLife.06253)

Leliavski A, Dumbell R, Ott V \& Oster H 2015 Adrenal clocks and the role of adrenal hormones in the regulation of circadian physiology. Journal of Biological Rhythms 30 20-34. (doi:10.1177/0748730414553971)

Leliavski A, Shostak A, Husse J \& Oster H 2014 Impaired glucocorticoid production and response to stress in Arntl-deficient male mice. Endocrinology 155 133-142. (doi:10.1210/en.2013-1531)

LeSauter J, Hoque N, Weintraub M, Pfaff DW \& Silver R 2009 Stomach ghrelin-secreting cells as food-entrainable circadian clocks. PNAS 106 13582-13587. (doi:10.1073/pnas.0906426106)

Marcheva B, Ramsey KM, Buhr ED, Kobayashi Y, Su H, Ko CH, Ivanova G, Omura C, Mo S, Vitaterna MH, et al. 2010 Disruption of the clock components CLOCK and BMAL1 leads to hypoinsulinaemia and diabetes. Nature 466 627-631. (doi:10.1038/nature09253)

Marcheva B, Ramsey KM, Peek CB, Affinati A, Maury E \& Bass J 2013 Circadian clocks and metabolism. Handbook of Experimental Pharmacology 217 127-155. (doi:10.1007/978-3-642-25950-0)

Mendoza J, Lopez-Lopez C, Revel FG, Jeanneau K, Delerue F, Prinssen E, Challet E, Moreau JL \& Grundschober C 2011 Dimorphic effects of leptin on the circadian and hypocretinergic systems of mice. Journal of Neuroendocrinology 23 28-38. (doi:10.1111/j.13652826.2010.02072.x)

Miller WL \& Bose HS 2011 Early steps in steroidogenesis: intracellular cholesterol trafficking. Journal of Lipid Research 12 2111-2135. (doi:10.1194/jlr.R016675)

Mistlberger RE \& Marchant EG 1999 Enhanced food-anticipatory circadian rhythms in the genetically obese Zucker rat. Physiology and Behavior 66 329-335. (doi:10.1016/S0031-9384(98)00311-4)

Mistlberger RE 2009 Food-anticipatory circadian concepts and methods. European Journal of Neuroscience 30 1718-1729. (doi:10.1111/j.14609568.2009.06965.x)

Moore RY \& Eichler VB 1972 Loss of a circadian adrenal corticosterone rhythm following suprachiasmatic lesions in the rat. Brain Research 42 201-206. (doi:10.1016/0006-8993(72)90054-6)
Okamura H 2007 Suprachiasmatic nucleus clock time in the mammalian circadian system. Cold Spring Harbor Symposia on Quantitative Biology 72 551-556. (doi:10.1101/sqb.2007.72.033)

Oster H, Damerow S, Kiessling S, Jakubcakova V, Abraham D, Tian J, Hoffmann MW \& Eichele G 2006 The circadian rhythm of glucocorticoids is regulated by a gating mechanism residing in the adrenal cortical clock. Cell Metabolism 4 163-173. (doi:10.1016/j. cmet.2006.07.002)

Ottenweller JE \& Meier AH 1982 Adrenal innervation may be an extrapituitary mechanism able to regulate adrenocortical rhythmicity in rats. Endocrinology 111 1334-1338. (doi:10.1210/ endo-111-4-1334)

Otway DT, Frost G \& Johnston JD 2009 Circadian rhythmicity in murine pre-adipocyte and adipocyte cells. Chronobiology International 26 1340-1354. (doi:10.3109/07420520903412368)

Owen BM, Bookout AL, Ding X, Lin VY, Atkin SD, Gautron L, Kliewer SA \& Mangelsdorf DJ 2013 FGF21 contributes to neuroendocrine control of female reproduction. Nature Medicine 19 1153-1156. (doi:10.1038/ nm.3250)

Paschos GK, Ibrahim S, Song WL, Kunieda T, Grant G, Reyes TM, Bradfield CA, Vaughan CH, Eiden M, Masoodi M, et al. 2012 Obesity in mice with adipocyte-specific deletion of clock component Arntl. Nature Medicine 18 1768-1777. (doi:10.1038/nm.2979)

Perelis M, Marcheva B, Ramsey KM, Schipma MJ, Hutchison AL, Taguchi A, Peek CB, Hong H, Huang W, Omura C, et al. 2015 Pancreatic beta cell enhancers regulate rhythmic transcription of genes controlling insulin secretion. Science $\mathbf{3 5 0}$ aac 4250 . (doi:10.1126/science.aac4250)

Perrin L, Loizides-Mangold U, Skarupelova S, Pulimeno P, Chanon S, Robert M, Bouzakri K, Modoux C, Roux-Lombard P, Vidal H, et al. 2015 Human skeletal myotubes display a cell-autonomous circadian clock implicated in basal myokine secretion. Molecular Metabolism 4 834-845. (doi:10.1016/j.molmet.2015.07.009)

Pincus G, Romanoff LP \& Carlo J 1954 The excretion of urinary steroids by men and women of various ages. Journal of Gerontology 9 113-132. (doi:10.1093/geronj/9.2.113)

Pocai A 2014 Action and therapeutic potential of oxyntomodulin. Molecular Metabolism 3 241-251. (doi:10.1016/j.molmet.2013.12.001)

Prosser RA \& Bergeron HE 2003 Leptin phase-advances the rat suprachiasmatic circadian clock in vitro. Neuroscience Letters 336 139-142. (doi:10.1016/S0304-3940(02)01234-X)

Ribeiro AC, Ceccarini G, Dupre C, Friedman JM, Pfaff DW \& Mark AL 2011 Contrasting effects of leptin on food anticipatory and total locomotor activity. PLOS ONE 6 e23364. (doi:10.1371/journal. pone.0023364)

Rossner MJ, Oster H, Wichert SP, Reinecke L, Wehr MC, Reinecke J, Eichele G, Taneja R \& Nave KA 2008 Disturbed clockwork resetting in Sharp-1 and Sharp-2 single and double mutant mice. PLOS ONE 3 e2762. (doi:10.1371/journal.pone.0002762)

Rudic RD, McNamara P, Curtis AM, Boston RC, Panda S, Hogenesch JB \& Fitzgerald GA 2004 BMAL1 and CLOCK, two essential components of the circadian clock, are involved in glucose homeostasis. PLoS Biology 2 e377. (doi:10.1371/journal.pbio.0020377)

Sadacca LA, Lamia KA, deLemos AS, Blum B \& Weitz CJ 2011 An intrinsic circadian clock of the pancreas is required for normal insulin release and glucose homeostasis in mice. Diabetologia 54 120-124. (doi:10.1007/s00125-010-1920-8)

Saeb-Parsy K, Lombardelli S, Khan FZ, McDowall K, Au-Yong IT \& Dyball RE 2000 Neural connections of hypothalamic neuroendocrine nuclei in the rat. Journal of Neuroendocrinology 12 635-648.

Saini C, Petrenko V, Pulimeno P, Giovannoni L, Berney T, Hebrok M, Howald C, Dermitzakis ET \& Dibner C 2016 A functional circadian clock is required for proper insulin secretion by human pancreatic islet cells. Diabetes, Obesity and Metabolism 18 355-365. (doi:10.1111/ dom.12616) http://joe.endocrinology-journals.org

DOI: $10.1530 / \mathrm{JOE}-16-0051$
(C) 2016 Society for Endocrinology Printed in Great Britain 
Schmutz I, Ripperger JA, Baeriswyl-Aebischer S \& Albrecht U 2010 The mammalian clock component PERIOD2 coordinates circadian output by interaction with nuclear receptors. Genes and Development $\mathbf{2 4}$ 345-357. (doi:10.1101/gad.564110)

Shi SQ, Ansari TS, McGuinness OP, Wasserman DH \& Johnson CH 2013 Circadian disruption leads to insulin resistance and obesity. Current Biology 23 372-381. (doi:10.1016/j.cub.2013.01.048)

Solt LA, Wang Y, Banerjee S, Hughes T, Kojetin DJ, Lundasen T, Shin Y, Liu J, Cameron MD, Noel R, et al. 2012 Regulation of circadian behaviour and metabolism by synthetic REV-ERB agonists. Nature $\mathbf{4 8 5}$ 62-68. (doi:10.1038/nature11030)

Son GH, Chung S, Choe HK, Kim HD, Baik SM, Lee H, Lee HW, Choi S, Sun W, Kim H, et al. 2008 Adrenal peripheral clock controls the autonomous circadian rhythm of glucocorticoid by causing rhythmic steroid production. PNAS 105 20970-20975. (doi:10.1073/ pnas.0806962106)

Spiga F, Walker JJ, Terry JR \& Lightman SL 2014 HPA axis-rhythms. Comprehensive Physiology 4 1273-1298.

Stephan FK \& Zucker I 1972 Circadian rhythms in drinking behavior and locomotor activity of rats are eliminated by hypothalamic lesions. PNAS 69 1583-1586. (doi:10.1073/pnas.69.6.1583)

Stephan FK 2002 The 'other' circadian food as a Zeitgeber. Journal of Biological Rhythms 17 284-292. (doi:10.1177/074873002129002591)

Storch KF \& Weitz CJ 2009 Daily rhythms of food-anticipatory behavioral activity do not require the known circadian clock. PNAS 106 6808-6813. (doi:10.1073/pnas.0902063106)

Sun X, Dang F, Zhang D, Yuan Y, Zhang C, Wu Y, Wang Y \& Liu Y 2015 Glucagon-CREB/CRTC2 signaling cascade regulates hepatic BMAL1 protein. Journal of Biological Chemistry 290 2189-2197. (doi:10.1074/ jbc.M114.612358)

Surjit M, Ganti KP, Mukherji A, Ye T, Hua G, Metzger D, Li M \& Chambon P 2011 Widespread negative response elements mediate direct repression by agonist-liganded glucocorticoid receptor. Cell 145 224-241. (doi:10.1016/j.cell.2011.03.027)

Szentirmai E, Kapas L, Sun Y, Smith RG \& Krueger JM 2010 Restricted feeding-induced sleep, activity, and body temperature changes in normal and preproghrelin-deficient mice. American Journal of Physiology: Regulatory, Integrative and Comparative Physiology 298 R467-R477.

Tahara Y, Otsuka M, Fuse Y, Hirao A \& Shibata S 2011 Refeeding after fasting elicits insulin-dependent regulation of Per2 and Rev-erbalpha with shifts in the liver clock. Journal of Biological Rhythms 26 230-240. (doi:10.1177/0748730411405958)

Terazono H, Mutoh T, Yamaguchi S, Kobayashi M, Akiyama M, Udo R, Ohdo S, Okamura H \& Shibata S 2003 Adrenergic regulation of clock gene expression in mouse liver. PNAS 100 6795-6800. (doi:10.1073/ pnas.0936797100)

Torres-Farfan C, Mendez N, Abarzua-Catalan L, Vilches N, Valenzuela GJ \& Seron-Ferre M 2011 A circadian clock entrained by melatonin is ticking in the rat fetal adrenal. Endocrinology 152 1891-1900. (doi:10.1210/en.2010-1260)

Torres-Farfan C, Richter HG, Rojas-Garcia P, Vergara M, Forcelledo ML, Valladares LE, Torrealba F, Valenzuela GJ \& Seron-Ferre M 2003 mt1 Melatonin receptor in the primate adrenal inhibition of adrenocorticotropin-stimulated cortisol production by melatonin. Journal of Clinical Endocrinology and Metabolism 88 450-458. (doi:10.1210/jc.2002-021048)

Tsang AH, Sanchez-Moreno C, Bode B, Rossner MJ, Garaulet M \& Oster H 2012 Tissue-specific interaction of Per1/2 and Dec2 in the regulation of fibroblast circadian rhythms. Journal of Biological Rhythms $\mathbf{2 7}$ 478-489. (doi:10.1177/0748730412462838)

Turek FW, Joshu C, Kohsaka A, Lin E, Ivanova G, McDearmon E, Laposky A, Losee-Olson S, Easton A, Jensen DR, et al. 2005 Obesity and metabolic syndrome in circadian Clock mutant mice. Science $\mathbf{3 0 8}$ 1043-1045. (doi:10.1126/science.1108750)

Ungar F \& Halberg F 1962 Circadian rhythm in the in vitro response of mouse adrenal to adrenocorticotropic hormone. Science $\mathbf{1 3 7}$ 1058-1060. (doi:10.1126/science.137.3535.1058)

Xu J, Lloyd DJ, Hale C, Stanislaus S, Chen M, Sivits G, Vonderfecht S, Hecht R, Li YS, Lindberg RA, et al. 2009 Fibroblast growth factor 21 reverses hepatic steatosis, increases energy expenditure, and improves insulin sensitivity in diet-induced obese mice. Diabetes 58 250-259. (doi:10.2337/db08-0392)

Yamajuku D, Inagaki T, Haruma T, Okubo S, Kataoka Y, Kobayashi S, Ikegami K, Laurent T, Kojima T, Noutomi K, et al. 2012 Real-time monitoring in three-dimensional hepatocytes reveals that insulin acts as a synchronizer for liver clock. Science Reports 2439.

Yamazaki S, Yoshikawa T, Biscoe EW, Numano R, Gallaspy LM, Soulsby S, Papadimas E, Pezuk P, Doyle SE, Tei H, et al. 2009 Ontogeny of circadian organization in the rat. Journal of Biological Rhythms $\mathbf{2 4}$ 55-63. (doi:10.1177/0748730408328438)

Yannielli PC, Molyneux PC, Harrington ME \& Golombek DA 2007 Ghrelin effects on the circadian system of mice. Journal of Neuroscience 27 2890-2895. (doi:10.1523/JNEUROSCI.3913-06.2007)

Yi CX, Challet E, Pevet P, Kalsbeek A, Escobar C \& Buijs RM 2008 A circulating ghrelin mimetic attenuates light-induced phase delay of mice and light-induced Fos expression in the suprachiasmatic nucleus of rats. European Journal of Neuroscience 27 1965-1972. (doi:10.1111/ j.1460-9568.2008.06181.x)

Yoder JM, Brandeland M \& Engeland WC 2014 Phase-dependent resetting of the adrenal clock by ACTH in vitro. American Journal of Physiology: Regulatory, Integrative and Comparative Physiology 306 R387-R393.

Zarrinpar A, Chaix A \& Panda S 2016 Daily eating patterns and their impact on health and disease. Trends in Endocrinology and Metabolism 27 69-83. (doi:10.1016/j.tem.2015.11.007)

Zhang EE \& Kay SA 2010 Clocks not winding unravelling circadian networks. Nature Reviews Molecular Cell Biology 11 764-776. (doi:10.1038/nrm2995)

Zhang R, Lahens NF, Ballance HI, Hughes ME \& Hogenesch JB 2014 A circadian gene expression atlas in implications for biology and medicine. PNAS 111 16219-16224. (doi:10.1073/ pnas.1408886111)

Zhao Y, Zhang Y, Zhou M, Wang S, Hua Z \& Zhang J 2012 Loss of mPer2 increases plasma insulin levels by enhanced glucose-stimulated insulin secretion and impaired insulin clearance in mice. FEBS Letters 586 1306-1311. (doi:10.1016/j.febslet.2012.03.034)

Received in final form 8 April 2016

Accepted 20 April 2016

Accepted Preprint published online 22 April 2016 http://joe.endocrinology-journals.org

DOI: 10.1530/JOE-16-0051
C 2016 Society for Endocrinology Printed in Great Britain
Published by Bioscientifica Ltd. 